\title{
Intensive Insulin Therapy Has No Effect on Mortality and Morbidity in Cardiac Surgery Patients: A Meta-Analysis
}

\author{
Kedar P. Kulkarni1,2, Ronald S. Chamberlain ${ }^{1,2,3^{*}}$ \\ ${ }^{1}$ Department of Surgery, Saint Barnabas Medical Center, Livingston, NJ, USA \\ ${ }^{2}$ Saint George's University School of Medicine, Grenada, West Indies \\ ${ }^{3}$ Department of Surgery, Rutgers University, New Jersey Medical School, Newark, NJ, USA \\ Email: *rchamberlain@barnabashealth.org
}

Received 13 July 2016; accepted 31 July 2016; published 3 August 2016

Copyright (C) 2016 by authors and Scientific Research Publishing Inc.

This work is licensed under the Creative Commons Attribution International License (CC BY). http://creativecommons.org/licenses/by/4.0/

(c) (i) Open Access

\section{Abstract}

Introduction: Optimal glycemic control in cardiac surgery patients remains a laudable but confusing practice. Existing studies have primarily employed two maintenance strategies using either intensive insulin therapy (IIT) (maintain glucose $<120 \mathrm{mg} / \mathrm{dl}$ ) or conventional insulin therapy (CIT) $(<200 \mathrm{mg} / \mathrm{dl})$ with conflicting outcomes. This meta-analysis evaluates the impact of IIT and CIT in regards to the incidence of mortality, length of stay (LOS), intensive care unit (ICU) LOS, atrial fibrillation (AF), and infections. Methods: A comprehensive literature search in PubMed, Google Scholar and the Cochrane Central Registry of Controlled Trials was completed between 1966 and 2016. Keywords searched were "insulin", "bypass", "coronary", "CABG", "glucose", "artery", "intensive", "cardiac", and "surgery". Eligible studies were randomized control trials (RCTs) comparing IIT (BGL 80-120 mg/dL) and CIT (BGL $<200 \mathrm{mg} / \mathrm{dL}$ ). Primary outcomes were mortality, ICU LOS, and hospital LOS. Results: 8 RCTs were included in this study. IIT strategies did not significantly affect overall mortality $(\mathrm{RR}=0.905,95 \% \mathrm{CI}=0.604$ to $1.356 ; p=0.628)$, ICU LOS (MD = -0.073 days, $95 \% \mathrm{CI}=-0.324$ to $0.178 ; p=0.568)$, or hospital LOS (MD $=0.269,95 \% \mathrm{CI}=-2.158$ to 2.696; $p=0.828)$. No difference in AF rates $(\mathrm{RR}=0.887,95 \% \mathrm{CI}=0.681$ to $1.155 ; p=0.375)$ or deep sternal infection $(\mathrm{RR}=0.985,95 \% \mathrm{CI}=0.357$ to $2.720 ; p=0.977)$ were observed. Conclusion: IIT targeting blood sugar levels of $80-120 \mathrm{mg} / \mathrm{dl}$ have no effect on perioperative outcomes in cardiac surgery patients. IIT is associated with similar mortality, ICU LOS, hospital LOS, AF rates, and deep sternal infection rates compared to more liberal glycemic strategies. IIT should not replace CIT as the standard of care in cardiac surgery patients.

"Corresponding author.

How to cite this paper: Kulkarni, K.P. and Chamberlain, R.S. (2016) Intensive Insulin Therapy Has No Effect on Mortality and Morbidity in Cardiac Surgery Patients: A Meta-Analysis. International Journal of Clinical Medicine, 7, 519-529. 
Keywords

Intensive Insulin Therapy, Tight Glycemic Control, Cardiac Surgery, CABG

\section{Introduction}

Hyperglycemia is a common occurrence in postoperative cardiac surgery patients and has been associated with detrimental clinical outcomes [1]. Several studies have documented that many patients undergoing coronary artery bypass grafting (CABG) often have blood glucose levels (BGLs) $>200 \mathrm{mg} / \mathrm{dL}$ despite no history of diabetes [2]-[5]. The consequences of elevated BGLs in cardiac surgery patients has been linked to increased mortality, higher rates of wound infections, and longer hospital stays [3] [4]. In an effort to optimize glycemic control in intensive care unit (ICU) patients, the American Diabetes Association (ADA) and the American Association of Clinical Endocrinologists (AACE) have recommended BGLs in the range of $140-180 \mathrm{mg} / \mathrm{dL}$ to balance the adverse effects of hyperglycemia and hypoglycemia [5].

Hyperglycemia, defined as a BGL of $>100 \mathrm{mg} / \mathrm{dL}$, is a normal occurrence in the post-prandial period. Persistent BGLs > $125 \mathrm{mg} / \mathrm{dL}$ for more than two hours after a meal is considered abnormal [5]. In the post-surgical period, hyperglycemia is not limited to those who have pre-existing insulin resistance or diabetes. Emotional and physical stresses experienced by surgical patients can cause "stress hyperglycemia" which is defined by the ADA and AACE as persistent BGLs $>140 \mathrm{mg} / \mathrm{dL}$ and a $\mathrm{HbA1C}$ of $<6.5 \%$ to rule out pre-existing diabetes [5].

Stress hyperglycemia is mediated by several hormones which affect glucose metabolism. Epinephrine increases gluconeogenesis in the liver and inhibits insulin secretion by the pancreas. Cortisol also increases hepatic gluconeogenesis while simultaneously increasing muscle catabolism to make more substrates for gluconeogenesis. Tumor Necrosis Factor Alpha (TNF- $\alpha$ ) directly reduces insulin sensitivity of cells by disrupting insulin receptor signaling. The combined effects of these stress hormones are thought to contribute to insulin resistance and consequently stress hyperglycemia. Insulin resistance also increases the concentration of free fatty acids (FFAs) in circulation which promote oxidative damage, disrupt the myocardial membrane, and inhibit glycolysis preventing cellular respiration in the ischemic conditions common to cardiac surgery [6].

Extensive research into stress hyperglycemia published by Van den Berghe et al. (2001),documented that surgical intensive care unit (SICU) patients experienced improved clinical outcomes, specifically related to morbidity and mortality, when the BGLs were maintained between 80 - $110 \mathrm{mg} / \mathrm{dL}$ [7]. Van den Berghe et al. (2006) subsequently reported no difference in mortality in IIT and CIT with an ICU population of surgical and nonsurgical patients [8]. The normoglycemia in Intensive Care Evaluation and Surviving Using Glucose Algorithm Regulation (NICE SUGAR) trial raised further suspicion about the efficacy of IIT by demonstrating a $2.6 \%$ increase in mortality in the IIT group [9]. One explanation for this increase in mortality was a lack of parenteral nutrition [9]. IIT's effect on mortality and morbidity in cardiac patients has remained controversial due to the conflicting outcomes of these studies. A previous systemic review by Haga et al. (2011) reported lower mortality and morbidity with IIT (defined as BGL $100-200 \mathrm{mg} / \mathrm{dL}$ ), compared to CIT (BLG $180-250 \mathrm{mg} / \mathrm{dL}$ ) [10]. This meta-analysis sought to further clarify whether BGLs below CIT would decrease mortality and morbidity specifically in cardiac surgery patients.

\section{Materials and Methods}

\subsection{Study Selection}

A literature search of all English published randomized control trials (RCTs) comparing IIT and CIT in postoperative cardiac surgery patients was conducted with PubMed, Google Scholar, Cochrane Central Registry of Controlled Trials (1966-2016). Additional citations were searched using references retrieved from prior publications. The last search was conducted on May 20th, 2016. Keywords used were all relevant combinations of "insulin”, "bypass", “coronary”, "CABG”, "glucose”, "artery”, "cardiac”, and "surgery” utilizing search operators "AND" or "OR" equivalents. Inclusion criteria consisted of RCTs with a target BGL of $80-120 \mathrm{mg} / \mathrm{dL}$ in the IIT group, a target BGL of $<200 \mathrm{mg} / \mathrm{dL}$ in the control group, and reported mortality. The search strategy utilized conformed to the Preferred Reporting Items for Systematic Reviews and Meta-Analysis (PRISMA) standards [11]. 


\subsection{Data Extraction}

Articles obtained from the above searches were reviewed for eligibility (Figure 1). Information regarding patients, intervention and control groups, as well as study methodology was extracted. The primary clinical outcomes of interest were mortality, ICU length of stay (LOS), and hospital LOS. Secondary outcomes were incidence of a trial fibrillation and deep sternal infection.

\subsection{Statistical Analysis}

For each study, relative risks (RR) with a 95\% confidence interval (CI) were calculated for the incidence of mortality, infection, and atrial fibrillation. Differences in means (MD) with a 95\% CI were calculated for ICU LOS, and hospital LOS. Meta-analysis of the pooled data was completed using Comparative Meta-Analysis software Version 3 (CMA v.3) (Biostat, Englewood, NJ, USA). A “0.5” continuity correction factor was applied to studies with an incidence of zero events to calculate the variance and RR. Both fixed-effects and random-effects models were considered, depending on the heterogeneity of the included studies. Heterogeneity between studies was assessed using both Cochrane's Q statistic and $\mathrm{I}^{2}$ statistic and $p<0.05$ or $\mathrm{I}^{2}>50$ was utilized as a cut-off for determining statistical significance. If there was significant heterogeneity, analysis was completed with a random-effects model whereas a fixed-effects model was used when there was no significant heterogeneity. For all outcomes, publication bias was assessed qualitatively with a funnel plot, as well as quantitatively with both Egger's and Begg's tests. For all statistical analysis, a two-tailed $p$-value of $<0.05$ was deemed statistically significant. A subgroup analysis comparing patients with and without diabetes was conducted.

\section{Results}

\subsection{Demographic Characteristics of the Studies}

8 RCTs involving 3541 patients met the inclusion criteria (Table 1). There were 1701 patients in the IIT group with a target BGL of $80-120 \mathrm{mg} / \mathrm{dL}$, and 1840 patients in the CIT group with a target BGL of $<200 \mathrm{mg} / \mathrm{dL}$.

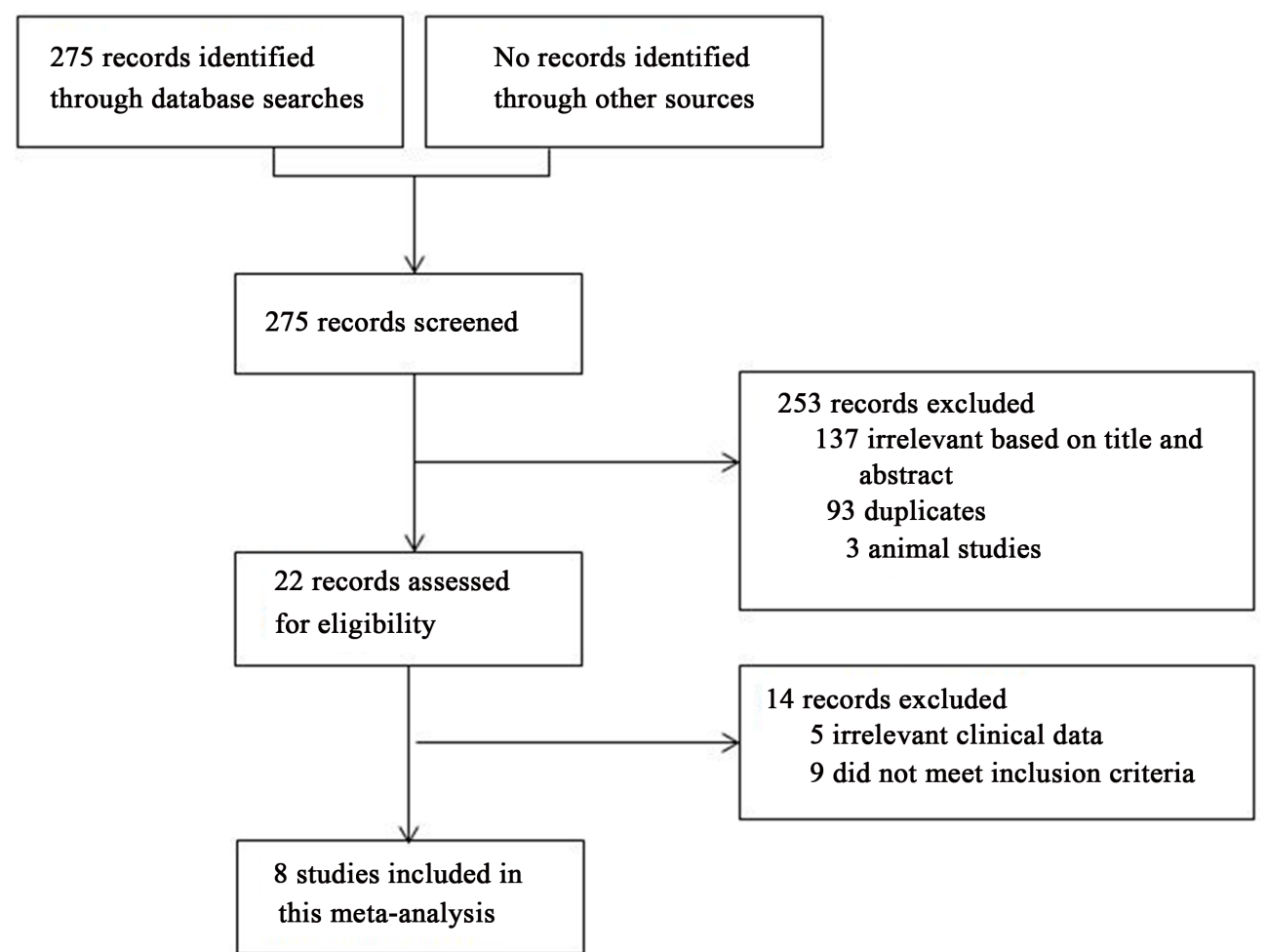

Figure 1. CONSORT diagram of the study selection process. 
Table 1. Characteristics of all published, randomized control trials comparing intensive insulin therapy and conventional insulin therapy in cardiac surgery patients that reported primary outcomes of mortality, intensive care unit length of stay, and hospital length of stay (1966-2016).

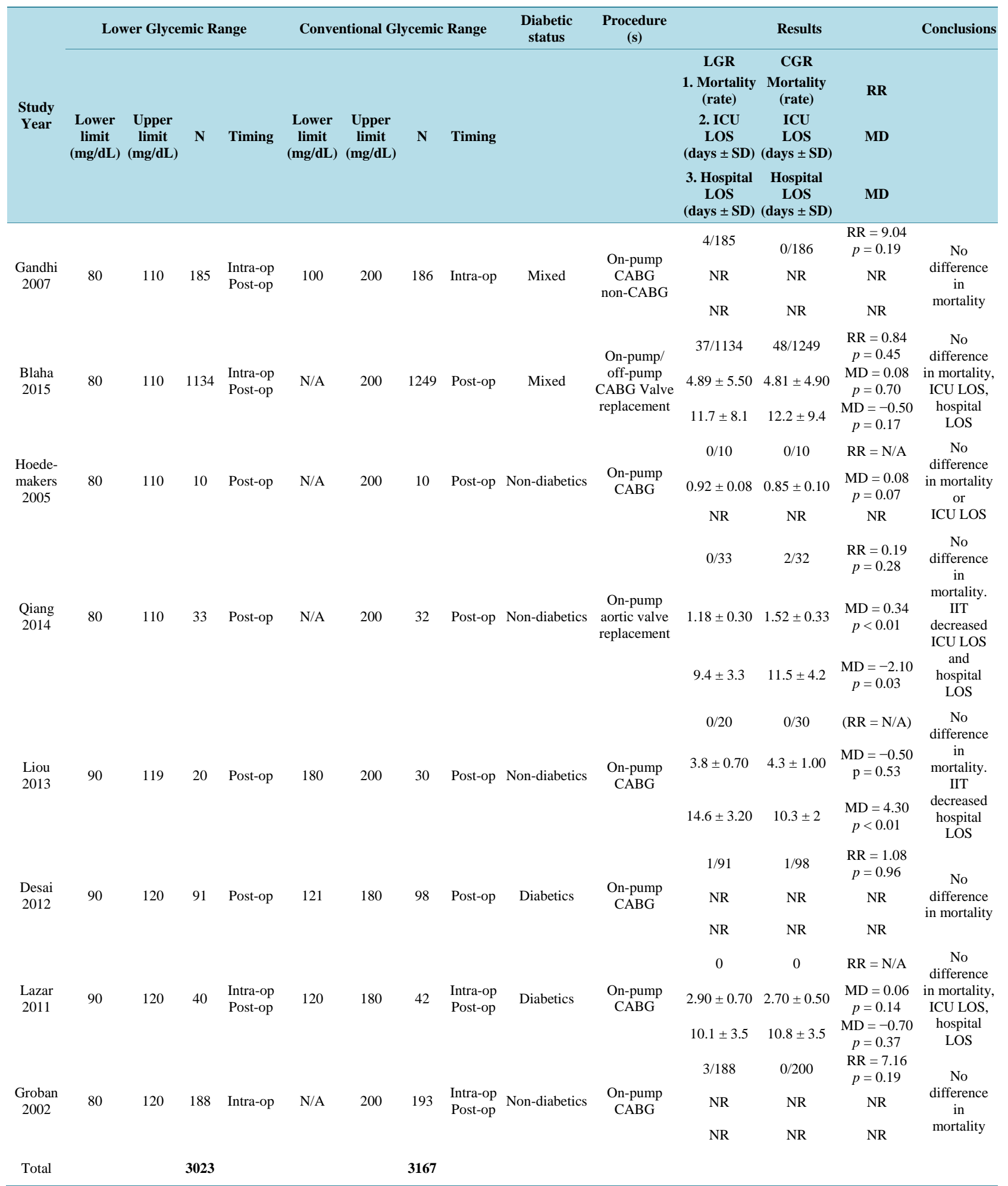

Abbreviations: mg/dL: milligrams/deciliter; N: number of patients; CABG: coronary artery bypass graft; intra-op: intraoperatively; post-op: postoperatively; RR: relative risk; MD: mean difference; SD: standard deviation; LGR: lower glycemic range; CGR: conventional glycemic range; NR: not reported; N/A: not applicable. 


\subsection{Effects of IIT on the Incidence of Mortality}

Overall mortality was reported in eight studies with 1701 patients in the IIT group and 1840 in the CIT group (Figure 2). There was no significant heterogeneity between trials ( $p=0.249, \mathrm{I}^{2}=25.9$ ) and a fixed effects model was used. There was no significant difference in mortality between the IIT group versus the CIT group (RR $=$ $0.905,95 \% \mathrm{CI}=0.604$ to $1.356 ; p=0.628)$.

Subgroup analysis identified no significant difference in mortality between IIT and CIT among diabetic (RR = $1.505,95 \% \mathrm{CI}=0.788$ to $2.878 ; p=0.216)$ and non-diabetic patients $(\mathrm{RR}=0.631,95 \% \mathrm{CI}=0.368$ to $1.081 ; p=$ 0.094). There was no significant heterogeneity observed between groups $(p=0.319)$.

\subsection{Effects of IIT on ICU LOS}

ICU LOS was reported in five trials involving 1237 patients in the IIT group and 1363 patients in the CIT group (Figure 3). A random effects model was used since there was significant heterogeneity between trials $(p<0.001$, $\mathrm{I}^{2}=86.0$ ). Meta-analysis revealed no significant difference in ICU LOS with IIT or CIT (MD $=-0.073$ days, $95 \%$ $\mathrm{CI}=-0.324$ to $0.178 ; p=0.568)$.

Subgroup analysis identified no significant difference in ICU LOS with the use of IIT among either diabetic $(\mathrm{MD}=0.155$ days, $95 \% \mathrm{CI}=-0.094$ to $0.405 ; p=0.222)$ or non-diabetic patients $(\mathrm{MD}=-0.019,95 \% \mathrm{CI}=-0.088$ to $0.050 ; p=0.594)$. There was no significant heterogeneity observed between groups $(p=0.245)$.

\begin{tabular}{|c|c|c|c|c|c|c|c|c|c|c|c|c|c|}
\hline \multirow[t]{2}{*}{$\underline{\text { Study name }}$} & \multicolumn{2}{|c|}{ Mortality/Total } & \multicolumn{4}{|c|}{$\underline{\text { Statistics for each study }}$} & \multicolumn{7}{|c|}{$\underline{\text { Risk ratio and } 95 \% \mathrm{Cl}}$} \\
\hline & IIT & $\mathrm{ClT}$ & $\begin{array}{l}\text { Risk } \\
\text { ratio }\end{array}$ & $\begin{array}{l}\text { Lower } \\
\text { limit }\end{array}$ & $\begin{array}{r}\text { Upper } \\
\text { limit }\end{array}$ & p-Value & & & & & & & \\
\hline Groban, 2002 & $23 / 188$ & $0 / 193$ & 7.185 & 0.374 & 138.162 & 0.191 & & & + & & & $\longrightarrow$ & \\
\hline Gandhi, 2007 & $74 / 185$ & $0 / 186$ & 9.048 & 0.491 & 166.879 & 0.139 & & & & & & & \\
\hline Desai, 2012 & $1 / 91$ & $1 / 98$ & 1.077 & 0.068 & 16.966 & 0.958 & & & & & & & \\
\hline Qiang, 2014 & $0 / 33$ & $2 / 32$ & 0.194 & 0.010 & 3.893 & 0.284 & & & & & & & \\
\hline \multirow{4}{*}{ Blaha, 2015} & $37 / 1134$ & $48 / 1249$ & 0.849 & 0.557 & 1.294 & 0.446 & & & & & & & \\
\hline & & & 0.905 & 0.604 & 1.356 & 0.628 & & & & & & & \\
\hline & & & & & & & 0.1 & 0.2 & 0.5 & 1 & 2 & 5 & 10 \\
\hline & & & & & & & \multicolumn{4}{|c|}{ Favors IIT } & \multicolumn{2}{|c|}{ Favors ClT } & \\
\hline
\end{tabular}

Figure 2. Forest plot evaluating the relative risk of mortality between intensive insulin therapy and conventional insulin therapy in cardiac surgery patients. Abbreviations: IIT: intensive insulin therapy; CIT: conventional insulin therapy; CI: confidence interval.

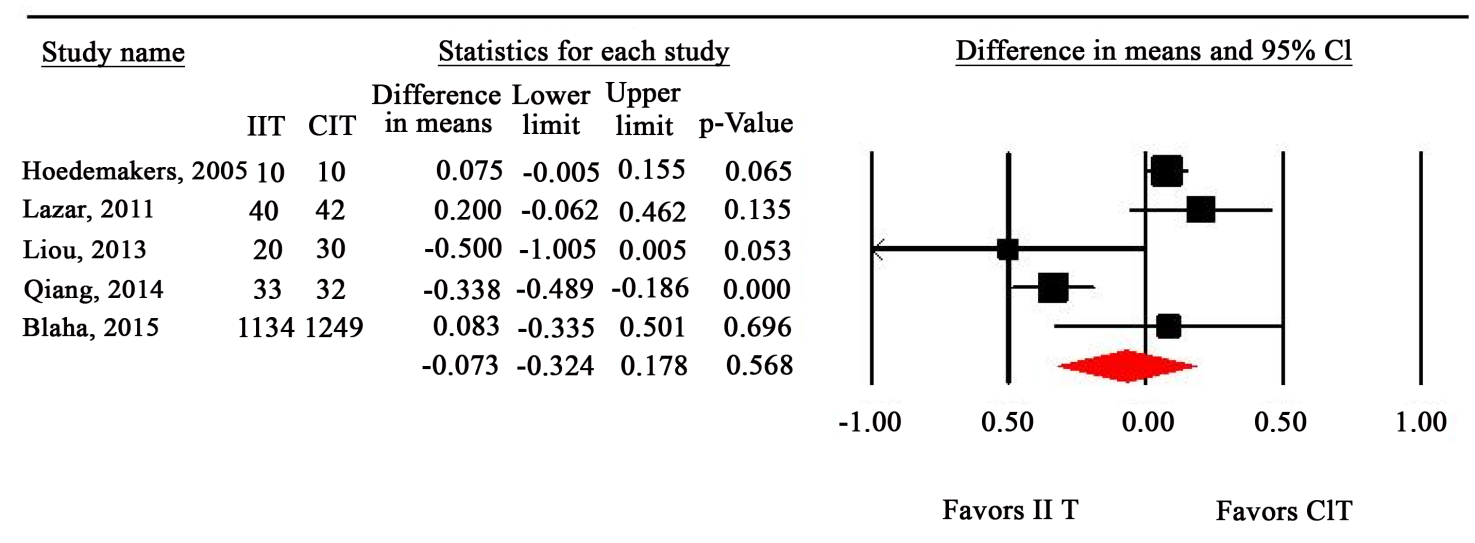

Figure 3. Forest plot evaluating the difference in means of intensive care unit length of stay between intensive insulin therapy and conventional insulin therapy in cardiac surgery patients. Abbreviations: IIT: intensive insulin therapy; CIT: conventional insulin therapy; CI: confidence interval. 


\subsection{Effects of IIT on Hospital LOS}

Hospital LOS was reported in four trials involving 1227 patients in the IIT group and 1353 patients in the CIT group (Figure 4). There was significant heterogeneity between studies $\left(p<0.001, \mathrm{I}^{2}=92.9\right)$, and a random effects model was used. Meta-analysis revealed no difference in mean hospital LOS (MD $=0.269$ days, $95 \% \mathrm{CI}=$ -2.158 to $2.696 ; p=0.828$ ).

Subgroup analysis identified no significant difference in hospital LOS with the use of IIT among either diabetic ( $\mathrm{MD}=-1.110$ days, $95 \% \mathrm{CI}=-2.228$ to $0.008 ; p=0.052$ ) or non-diabetic patients $(\mathrm{MD}=0.759,95 \% \mathrm{CI}=-2.435$ to 3.953; $p=0.641)$. There was no significant heterogeneity observed between groups ( $p=0.279$ ).

\subsection{Effects of IIT on Deep Sternal Infection}

Deep sternal wound infections were reported in three trials involving 316 patients in the IIT group and 326 patients in the CIT group (Figure 5). There was no significant heterogeneity between trials $\left(p=0.441, \mathrm{I}^{2}<0.001\right.$ ), and a fixed effects model was used. Meta-analysis revealed no significant difference in infection (RR=0.985, 95\% $\mathrm{CI}=0.357$ to $2.720 ; p=0.977)$.

\subsection{Effects of IIT on Atrial Fibrillation}

Atrial fibrillation was reported in three studies involving 316 patients in the IIT group and 326 patients in the CIT group (Figure 6). There was no significant heterogeneity between trials $\left(p=0.898, \mathrm{I}^{2}<0.001\right.$ ), and a fixed effects model was used. Meta-analysis revealed no significant difference in the risk of atrial fibrillation between IIT or CIT $(\mathrm{RR}=0.887,95 \% \mathrm{CI}=0.681$ to $1.155 ; p=0.375)$.

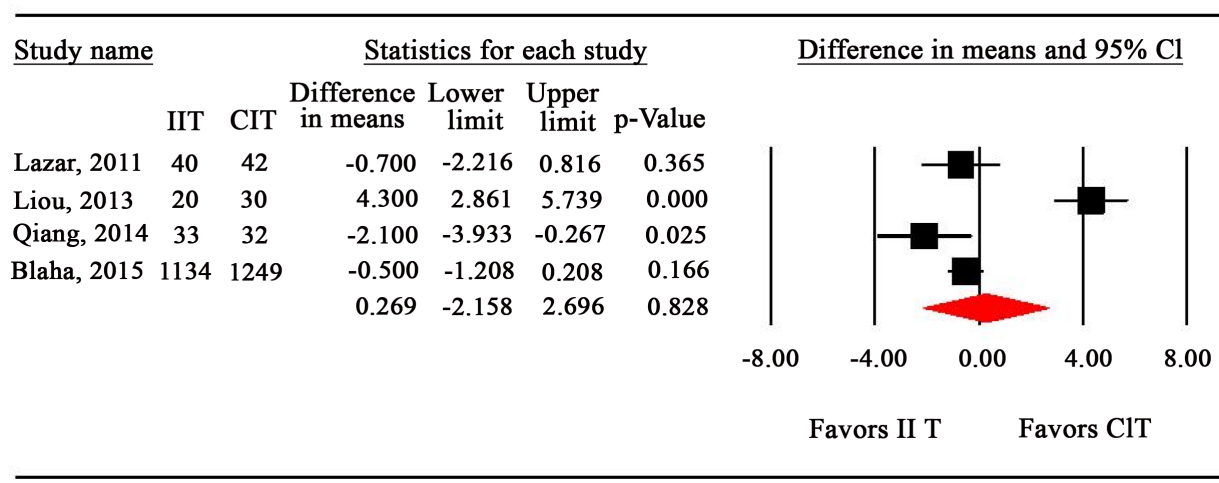

Figure 4. Forest plot evaluating the difference in means of hospital length of stay between intensive insulin therapy and conventional insulin therapy in cardiac surgery patients. Abbreviations: IIT: intensive insulin therapy; CIT: conventional insulin therapy; CI: confidence interval.

\begin{tabular}{|c|c|c|c|c|c|c|c|c|c|c|c|c|c|}
\hline Study name & Mortali & ty/Total & $\underline{\text { Stat }}$ & tistics fo & or each & study & & & sk ra & 0 anc & $95 \%$ & & \\
\hline & IIT & $\mathrm{ClT}$ & $\begin{array}{l}\text { Risk } \\
\text { ratio }\end{array}$ & $\begin{array}{c}\text { Lower } \\
\text { limit }\end{array}$ & $\begin{array}{c}\text { Upper } \\
\text { limit }\end{array}$ & p-Value & & & & & & & \\
\hline Gandhi, 2007 & $54 / 185$ & $59 / 186$ & 0.920 & 0.676 & 1.252 & 0.597 & & 1 & & & & | & \\
\hline Lazar, 2011 & $12 / 40$ & $16 / 42$ & 0.788 & 0.428 & 1.450 & 0.443 & & & & & & & \\
\hline Desai, 2012 & $7 / 91$ & 9/98 & 0.838 & 0.325 & 2.156 & 0.713 & & & & & & & \\
\hline & & & 0.887 & 0.681 & 1.155 & 0.375 & & & & & & & \\
\hline & & & & & & & 0.1 & 0.2 & 0.5 & 1 & 2 & 5 & 10 \\
\hline & & & & & & & & Fav & IIT & & & $\mathrm{ClT}$ & \\
\hline
\end{tabular}

Figure 5. Forest plot evaluating the relative risk of atrial fibrillation between intensive insulin therapy and conventional insulin therapy in cardiac surgery patients. Abbreviations: IIT: intensive insulin therapy; CIT: conventional insulin therapy; CI: confidence interval. 


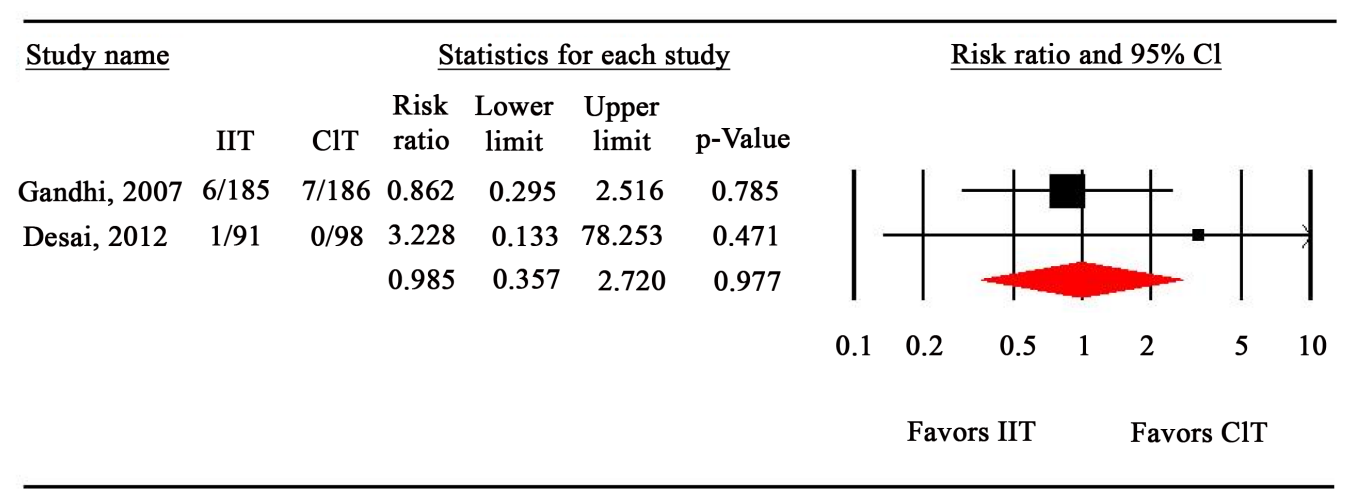

Figure 6. Forest plot evaluating the relative risk of deep sternal infections between intensive insulin therapy and conventional insulin therapy in cardiac surgery patients. Abbreviations: IIT: intensive insulin therapy; CIT: conventional insulin therapy; CI: confidence interval.

\subsection{Publication Bias}

Publication bias among the studies was completed first with a funnel plot. In addition, Egger's and Begg's tests were calculated to determine publication bias. There was no evidence of asymmetry on the funnel plots. In addition, there was no evidence of publication bias for the primary outcome of mortality observed by the Eggers ( $p=$ $0.440)$ or Begg's test $(p=0.807)$.

\section{Discussion}

Post-operative hyperglycemia in cardiac surgery patients is associated with increased mortality, infection, and length of stay [1]. With up to $80 \%$ of cardiac surgery patients experiencing hyperglycemia, methods to decrease associated complications are necessary [2]. Current guidelines by the Society of Thoracic Surgeons recommend maintaining BGLs below $200 \mathrm{mg} / \mathrm{dL}$ with a target range of 140-180 mg/dL to reduce hypoglycemia [3]. This meta-analysis sought to determine whether IIT could further reduce postoperative mortality and morbidity experienced by cardiac surgery patients.

The results of this meta-analysis demonstrated no significant difference in mortality, ICU LOS, hospital LOS, infection, or atrial fibrillation rates among post-cardiac surgery patients treated with IIT. Furthermore, subgroup analysis identified no significant difference in morbidity and mortality among patients with or without diabetes.

In addition to hyperglycemia, several other factors have been linked to increased mortality in cardiac surgery patients, including prolonged aortic cross clamp time, low left ventricular ejection fraction (LVEF), arrhythmias including atrial fibrillation, inotrope use, and renal failure [12]-[14]. LVEF $<30 \%$ has also been associated with increased mortality independent of cross clamp times [15]. Prevention of hyperglycemia has been independently linked to a reduction in risk factors associated with mortality [10]. While this study finds no difference between IIT and CIT, several studies have suggested IIT is safe and optimizing its usage may decrease mortality and morbidity [16].

IIT has been reported to be linked to increased mortality, presumably secondary to hypoglycemia [9]. Whether iatrogenic hypoglycemia, as experienced by IIT patients, is a major risk factor for mortality is debatable [17]. Hypoglycemia can be subdivided into iatrogenic and spontaneous causes which are difficult to distinguish in a clinical setting [17]. Several studies have observed that spontaneous hypoglycemia, rather than iatrogenic, is a more significant predictor of mortality [17]-[20]. Arabi et al. reported that IIT was associated with increased risk of hypoglycemia (OR $=50.65 ; p<0.001)$ but no difference in mortality $(p=0.40)$ [17]. A cohort of 2538 cardiac surgery patients studied by Stamou et al. also yielded no difference in mortality in IIT patients with hypoglycemic episodes $(p=0.11)$ [18]. Furthermore, Boucai et al. reported that iatrogenic hypoglycemia after initiation of anti-hyperglycemic medication, such as insulin, was not associated with mortality $(\mathrm{HR}=1.06 ; p=0.749)$, while spontaneous hypoglycemia significantly increased mortality (HR $=2.62 ; p<0.001)$ [19]. Similarly, in a cohort study of 7820 acute myocardial infarction patients by Kosiborod et al., spontaneous hypoglycemia among patients who were not treated with insulin was a stronger predictor of mortality $(\mathrm{OR}=2.32)$ compared to those treated with insulin and experiencing iatrogenic hypoglycemia $(\mathrm{OR}=0.92)$ [20]. These studies demon- 
strate iatrogenic hypoglycemia, as experienced in a critical care setting, is not associated with mortality to the same extent as spontaneous hypoglycemia.

Reducing glycemic variability, a measure of how much BGLs fluctuate, has also been linked to lower mortality. Meyfroidt et al. examined the results of the two Van den Berghe et al. (2001 \& 2006) studies, and demonstrated that patients with low daily BGL range fluctuation $(0-4 \mathrm{mmol} / \mathrm{dL})$ had decreased mortality versus patients with high BGL fluctuation ( $>6 \mathrm{mmol} / \mathrm{dL}$ ) (15.3 vs 35.5\%; $p<0.001)$ [21]. Similarly, a cohort study of $194,772$ patients by Badawi et al. reported higher mortality (OR $=1.67 ; p<0.001)$ in patients with the high BGL fluctuations. A retrospective study of 44,964 patients by Krinsley et al. (2013) also observed an increase in mortality when glycemic variability, defined as a coefficient of variation $>20 \%$, was present $(9.2 \%$ vs $36.7 \%$; $p<0.001$ ) [16]. While the most optimal IIT range remains uncertain, reduced glycemic variability has been consistently shown to decrease mortality.

Patients with diabetes have also been reported to benefit from IIT. Van den Berghe et al. (2006) reported no increase in mortality when diabetic ICU patients were managed with IIT [8]. However, in a study involving cardiac surgery patients, Lazar et al. (2004) reported no difference in mortality with the use of IIT targeting BGL < $140 \mathrm{mg} / \mathrm{dL}$, but did demonstrate reduced atrial fibrillation rates, LOS, and a 2-year survival advantage [22]. Krinsley et al. (2013) observed reduced mortality in diabetics (OR $=0.93 ; p=0.003$ ) regardless of BGL range [16]. These authors also noted that diabetics had lower mortality with a BGL of $110-140 \mathrm{mg} / \mathrm{dL}$ versus $80-110$ $\mathrm{mg} / \mathrm{dL}(12.6 \%$ vs $15.3 \% ; p<0.001)[16]$.

The duration of IIT may also be a factor in its effectiveness. Van den Berghe et al. (2001) demonstrated IIT managed patients with an ICU stay $>5$ days had shorter duration of mechanical ventilation $(p=0.006)$, and lower incidence of renal impairment $(p=0.04)$, hyperbilirubinemia $(p=0.04)$, septicemia $(p=0.003)$, and polyneuropathy $(p<0.001)$ [7]. Mortality was also significantly lower in IIT patients with ICU stays $>5$ days (10.2\% vs. 20.2\%; $p=0.005$ ), but no benefit in either mortality or morbidity was observed among patients with ICU stays $<5$ days [7]. In a later study, Van den Berghe et al. (2006) also reported decreased morbidity and mortality ( $52.5 \%$ vs. $43.0 \%$; $p=0.009)$ in a mixed medical/surgical ICU population with ICU stays $>3$ days, but no difference in ICU stays $<3$ days [8]. Furnary et al. (2006) further observed that reduction in the 3-day average blood glucose after CABG in diabetic patients was associated with lower mortality [23]. These studies suggest a duration of 3 days for IIT to be effective.

The benefit of IIT in cardiac surgery patients may be due to insulin's anti-inflammatory properties. Inflammatory markers such as interleukin-6 (IL-6), tumor necrosis factor alpha (TNF-alpha), and C-reactive protein (CRP) are elevated in the post-cardiac surgery period [24]. All three are implicated in insulin resistance, which promotes hyperglycemia, further increasing inflammation in a positive feedback loop [25]. Insulin may break this loop by preventing hyperglycemia [25].

Despite no observed reduction in patient morbidity and mortality, IIT has been reported to reduce inflammation and post-operative complications [24]-[27]. Atrial fibrillation has been linked to inflammation through elevated CRP levels by both Bruins et al. and Aviles et al. (OR = 1.8; $p=0.002)$ [28] [29]. Stegenga et al. reported increased stroke incidence with hyperglycemia, and Capps et al. reported that negative outcomes for stroke patients were directly proportional to the level of hyperglycemia [30] [31]. Azevedo et al. reported a trend towards favorable outcomes, in terms of Risk, Injury, Failure, Loss, End-stage kidney disease (RIFLE) criteria, in renal failure with IIT, and an increase in poor outcomes proportional to the level of hyperglycemia [32]. These studies together support the role of IIT in ameliorating complications after cardiac surgery.

There are limitations to this study due to variation and heterogeneity of the RCTs. Protocols for the management of blood glucose varied between studies. Blood glucose was measured at different intervals and using different methods. In addition, exclusively intra-operative use of IIT was explored by some studies. Additional studies to determine the optimal protocol for reducing glycemic variability and hypoglycemia with appropriate duration of IIT are required. Methods by which this may be achieved are the use of an artificial pancreas, supplemental nutrition, and continuing IIT for a minimum of 3 days' duration.

Despite the limitations discussed, this study identified no significant difference in patient outcomes including mortality, ICU LOS, hospital LOS, atrial fibrillation or infection with the use of IIT compared to CIT in cardiac surgery patients. Given the large number of cardiac surgery procedures performed worldwide, the cost of prolonged ICU stays, and the absence of benefit to patients, IIT should not be the preferred method for the management of glycemic control in cardiac surgery patients. 


\section{References}

[1] Schmeltz, L.R., DeSantis, A.J., Thiyagarajan, V., et al. (2007) Reduction of Surgical Mortality and Morbidity in Diabetic Patients Undergoing Cardiac Surgery with a Combined Intravenous and Subcutaneous Insulin Glucose Management Strategy. Diabetes Care, 30, 823-828.

[2] Furnary, A.P., Wu, Y. and Bookin, S.O. (2004) Effect of Hyperglycemia and Continuous Intravenous Insulin Infusion on Outcomes of Cardiac Surgical Procedures: The Portland Diabetic Project. Endocrine Practice, 10, 21-33. http://dx.doi.org/10.4158/EP.10.S2.21

[3] Donner, T.W. and Flammer, K.M. (2008) Diabetes Management in the Hospital. Medical Clinics of North America, 92, 407-425. http://dx.doi.org/10.1016/j.mcna.2007.10.001

[4] Van den Berghe, G., Wouters, P.J., Bouillon, R., et al. (2003) Outcome Benefit of Intensive Insulin Therapy in the Critically Ill: Insulin Dose versus Glycemic Control. Critical Care Medicine, 31, 359-366. http://dx.doi.org/10.1097/01.CCM.0000045568.12881.10

[5] American Diabetes Association (2005) Diabetes Mellitus and Other Categories of Description of Diabetes. American Diabetes Association, 28, s5-s10. http://dx.doi.org/10.2337/diacare.27.2007.S5

[6] Dungan, K.M., Braithwaite, S.S. and Preiser, J.C. (2009) Stress Hyperglycaemia. Lancet, 373, 1798-1807. http://dx.doi.org/10.1016/S0140-6736(09)60553-5

[7] van den Berghe, G., Wouters, P., Weekers, F., et al. (2001) Intensive Insulin Therapy in the Critically Ill Patients. New England Journal of Medicine, 345, 1359-1367. http://dx.doi.org/10.1056/NEJMoa011300

[8] Van Den Berghe, G., Wilmer, A., Milants, I., et al. (2006) Intensive Insulin Therapy in Mixed Medical/Surgical. Heal, 55, 3151-3159. http://dx.doi.org/10.2337/db06-0855

[9] Finfer, S., Chittock, D.R., Su, S.Y.-S., et al. (2009) Intensive versus Conventional Glucose Control in Critically Ill Patients. New England Journal of Medicine, 360, 1283-1297. http://dx.doi.org/10.1056/NEJMoa0810625

[10] Haga, K.K., McClymont, K.L., Clarke, S., et al. (2011) The Effect of Tight Glycaemic Control, during and after Cardiac Surgery, on Patient Mortality and Morbidity: A Systematic Review and Meta-Analysis. Journal of Cardiothoracic Surgery, 6, 3. http://dx.doi.org/10.1186/1749-8090-6-3

[11] Liberati, A., Altman, D.G., Tetzlaff, J., et al. (2009) Annals of Internal Medicine Academia and Clinic the PRISMA Statement for Reporting Systematic Reviews and Meta-Analyses of Studies That Evaluate Health Care Interventions : Annals of Internal Medicine, 151, W65-W94. http://dx.doi.org/10.1371/journal.pmed.1000100

[12] Nashef, S.A.M., Roques, F., Michel, P., Gauducheau, E., Lemeshow, S. and Salamon, R. (1999) European System for Cardiac Operative Risk Evaluation (EuroSCORE). European Journal Cardio-Thoracic Surgery, 16, 9-13. http://dx.doi.org/10.1016/S1010-7940(99)00134-7

[13] Al-Sarraf, N., Thalib, L., Hughes, A., et al. (2011) Cross-Clamp Time Is an Independent Predictor of Mortality and Morbidity in Low- and High-Risk Cardiac Patients. International Journal of Surgery, 9, 104-109. http://dx.doi.org/10.1016/j.ijsu.2010.10.007

[14] El-Chami, M.F., Kilgo, P., Thourani, V., et al. (2010) New-Onset Atrial Fibrillation Predicts Long-Term Mortality After Coronary Artery Bypass Graft. Journal of the American College of Cardiology, 55, 1370-1376. http://dx.doi.org/10.1016/j.jacc.2009.10.058

[15] Doenst, T., Borger, M.A., Weisel, R.D., Yau, T.M., Maganti, M. and Rao, V. (2008) Relation between Aortic CrossClamp Time and Mortality—Not as Straightforward as Expected. European Journal Cardio-Thoracic Surgery, 33, 660-665. http://dx.doi.org/10.1016/j.ejcts.2008.01.001

[16] Krinsley, J.S., Egi, M., Kiss, A., et al. (2013) Diabetic Status and the Relation of the Three Domains of Glycemic Control to Mortality in Critically Ill Patients: An International Multicenter Cohort Study. Critical Care, 17, R37. http://dx.doi.org/10.1186/cc12547

[17] Arabi, Y.M., Tamim, H.M. and Rishu, A.H. (2009) Hypoglycemia with Intensive Insulin Therapy in Critically ill Patients: Predisposing Factors and Association with Mortality. Critical Care Medicine, 37, 2536-2544. http://dx.doi.org/10.1097/CCM.0b013e3181a381ad

[18] Stamou, S.C., Nussbaum, M., Carew, J.D., et al. (2011) Hypoglycemia with Intensive Insulin Therapy after Cardiac Surgery: Predisposing Factors and Association with Mortality. The Journal of Thoracic and Cardiovascular Surgery, 142, 166-173. http://dx.doi.org/10.1016/j.jtcvs.2010.09.064

[19] Boucai, L., Southern, W.N. and Zonszein, J. (2011) Hypoglycemia-Associated Mortality Is Not Drug-Associated but Linked to Comorbidities. American Journal of Medicine, 124, 1028-1035. http://dx.doi.org/10.1016/j.amjmed.2011.07.011

[20] Kosiborod, M., Inzucchi, S.E., Goyal, A., et al. (2009) Relationship between Spontaneous and Iatrogenic Hypoglycemia and Mortality in Patients Hospitalized with Acute Myocardial Infarction. JAMA, 301, 1556-1564. 
http://dx.doi.org/10.1001/jama.2009.496

[21] Meyfroidt, G., Keenan, D.M., Wang, X., Wouters, P.J., Veldhuis, J.D. and van den Berghe, G. (2010) Dynamic Characteristics of Blood Glucose Time Series during the Course of Critical Illness: Effects of Intensive Insulin Therapy and Relative Association with Mortality. Critical Care Medicine, 38, 1021-1029. http://dx.doi.org/10.1097/CCM.0b013e3181cf710e

[22] Lazar, H.L., Chipkin, S.R., Fitzgerald, C., Bao, Y., Cabral, H. and Apstein, C.S. (2004) Tight Glycemic Control in Diabetic Coronary Artery Bypass Graft Patients Improves Perioperative Outcomes and Decreases Recurrent Ischemic Events. Circulation, 109, 1497-1502. http://dx.doi.org/10.1161/01.CIR.0000121747.71054.79

[23] Furnary, A.P. and Wu, Y. (2006) Eliminating the Diabetic Disadvantage: The Portland Diabetic Project. Seminars in Thoracic and Cardiovascular Surgery, 18, 302-308. http://dx.doi.org/10.1053/j.semtcvs.2006.04.005

[24] Paparella, D., Yau, T.M. and Young, E. (2002) Cardiopulmonary Bypass Induced Inflammation: Pathophysiology and Treatment. An Update. European Journal Cardio-Thoracic Surgery, 21, 232-244. http://dx.doi.org/10.1016/S1010-7940(01)01099-5

[25] Ndumele, C.E., Pradhan, A.D. and Ridker, P.M. (2006) Interrelationships between Inflammation, C-Reactive Protein, and Insulin Resistance. Journal of the CardioMetabolic Syndrome, 1, 107-196. http://dx.doi.org/10.1111/j.1559-4564.2006.05538.x

[26] Hoedemaekers, C.W., Pickkers, P., Netea, M.G., van Deuren, M. and Van der Hoeven, J.G. (2005) Intensive Insulin Therapy Does Not Alter the Inflammatory Response in Patients Undergoing Coronary Artery Bypass Grafting: A Randomized Controlled Trial [ISRCTN95608630]. Critical Care, 9, R790-R797. http://dx.doi.org/10.1186/cc3911

[27] Kalman, J.M., Munawar, M., Howes, L.G., et al. (1995) Atrial Fibrillation after Coronary Artery Bypass Grafting Is Associated with Sympathetic activation. Annals of Thoracic Surgery, 60, 1709-1715. http://dx.doi.org/10.1016/0003-4975(95)00718-0

[28] Aviles, R.J., Martin, D.O., Apperson-Hansen, C., et al. (2003) Inflammation as a Risk Factor for Atrial Fibrillation. Circulation, 108, 3006-3010. http://dx.doi.org/10.1161/01.CIR.0000103131.70301.4F

[29] Bruins, P., Te, V.H., Yazdanbakhsh, A.P., et al. (1997) Activation of the Complement System during and after Cardiopulmonary Bypass Surgery: Postsurgery Activation Involves C-Reactive Protein and Is Associated with Postoperative Arrhythmia. Circulation, 96, 3542-3548. http://dx.doi.org/10.1161/01.CIR.96.10.3542

[30] Capes, S.E., Hunt, D., Malmberg, K., Pathak, P. and Gerstein, H.C. (2001) Stress Hyperglycemia and Prognosis of Stroke in Nondiabetic and Diabetic Patients: A Systematic Overview. Stroke, 32, 2426-2432. http://dx.doi.org/10.1161/hs1001.096194

[31] Stegenga, M.E., van der Crabben, S.N., Blümer, R.M.E., et al. (2008) Hyperglycemia Enhances Coagulation and Reduces Neutrophil Degranulation, Whereas Hyperinsulinemia Inhibits Fibrinolysis during Human Endotoxemia. Blood, 112, 82-89. http://dx.doi.org/10.1182/blood-2007-11-121723

[32] Azevedo, J.R.A., Azevedo, R.P., Lucena, L.C., Costa, N.N.R. and Sousa, W.S. (2009) Does Intensive Insulin Therapy Really Reduce the Incidence of Acute Renal Injury in Critically Ill Patients? An Analysis Using the RIFLE Criteria. Critical Care, 13, P37. http://dx.doi.org/10.1186/cc7839 http://ovidsp.ovid.com/ovidweb.cgi?T=JS\&PAGE=reference\&D=emed10\&NEWS=N\&AN=70339953 


\section{Abbreviation List}

IIT: Intensive insulin therapy

mg: Milligrams

dl: Deciliters

CIT: Conventional insulin therapy

ICU: Intensive care unit

LOS: Length of stay

AF: Atrial fibrillation

CABG: Coronary artery bypass graft

RCT: Randomized control trials

BGL: Blood glucose levels

MD: Mean difference

RR: Relative risk

CI: Confidence interval

ADA: American diabetes association

AACE: American association of clinical endocrinologists

TNF- $\alpha$ : Tumor necrosis factor alpha

FFA: Free fatty acid

CRP: C-reactive protein

IL: Interleukin

RIFLE: Risk, injury, failure, loss, end-stage kidney disease

SICU: Surgical intensive care unit

\section{Submit or recommend next manuscript to SCIRP and we will provide best service for you:}

Accepting pre-submission inquiries through Email, Facebook, LinkedIn, Twitter, etc.

A wide selection of journals (inclusive of 9 subjects, more than 200 journals)

Providing 24-hour high-quality service

User-friendly online submission system

Fair and swift peer-review system

Efficient typesetting and proofreading procedure

Display of the result of downloads and visits, as well as the number of cited articles

Maximum dissemination of your research work

Submit your manuscript at: http://papersubmission.scirp.org/ 